\title{
Characteristics of the soil microbial population in forest land irrigated with saline water in the desert area
}

\author{
ZhengZhong $\mathrm{JIN}^{1,2^{*}}$, JiaQiang LEI ${ }^{1}$, XinWen $\mathrm{XU}^{1}$, ShengYu $\mathrm{LI}^{1}$, JingLong FAN ${ }^{1}$, SiFeng ZHAO ${ }^{3}$ \\ ${ }^{1}$ Xinjiang Institute of Ecology and Geography, Chinese Academy of Sciences, Urumqi 830011, China; \\ ${ }^{2}$ Key Laboratory of Oasis Ecology and Desert Environment, Xinjiang Institute of Ecology and Geography, Chinese Academy of \\ Sciences, Urumqi 830011, China; \\ ${ }^{3}$ Agricultural College of Shihezi University, Shihezi 832003, China
}

\begin{abstract}
The study of soil microbial populations and diversity is an important way to understanding the soil energy process. In this study we analyzed the characteristics of soil microbial populations of the Tarim Desert Highway shelter-forest, by identifying microbial fatty acids and using methods of conventional cultivation. The results illustrated that the amount of soil microbial activity and the diversity of soil microbial fatty acid increased significantly with the plantation age of the shelter-forest; the soil microbial population was dominated by bacteria. The fatty acids of C14:0, C15:0, C16:0, C17:0, C18:1w9, C18:0, C18 : $2 \omega 6$ and C21: 0 were found to be dominant soil microbial fatty acids in the shelter-forest soil. Principal analysis and regression analysis showed that (1) concentrations of fatty acids of C14:0, C16:0 and C18: 0 could be used as indicators of total soil microbial population; (2) soil bacteria and actinomycetes populations were closely correlated with the amount of fatty acids of $\mathrm{C} 15: 0$ and $\mathrm{C} 17: 0$; and (3) soil fungi were closely correlated with the amount of fatty acids of $C 18: 1 \omega 9$ and $C 18: 2 \omega 6$.
\end{abstract}

Keywords: desert; shelter forest; soil microbial population; phospholipids fatty acid

\section{Introduction}

The Tarim Desert Highway, located in the Tarim Basin of China, is important to exploration of oil and gas resources in Tarim Basin, the economy and social developments in Southern Xinjiang, and in the stability of the border areas. In order to ensure the uninterrupted flow of traffic along the highway, an ecological shelterbelt project was established along the highway to reduce the effects of shifting sand. However, adverse natural conditions, mainly due to the mobile sand, have frequently threatened the shelterbelt (Zhou et al., 2006). Therefore, the ecological stability of the shelterbelt along the Tarim Desert Highway is important. The forest shelterbelt has caused soil environmental changes, especially in soil microbial populations (Shan et al., 2001; Gu et al., 2002).

As an important component of soil ecosystems, soil microbes participate in soil bioactivity, such as energy fluxion, nutrient cycling and organism transportation. Recently, many studies on soil microbial community structure have been reported, which focus on identifying and predicting environmental changes by using variations in microbial structure as indicators. Identification of fatty acids, conventional cultivation of microbes and methods of molecular biology were used in such research to isolate the soil microbes involved (Salomo 2009; Mitchell et al., 2010; Moore et al., 2010).

Forestland soil microorganisms, involved in soil energy cycling processes, play an important role in producing available nutrients for the forest trees (Moscatelli et al., 2001). Soil microbial diversity influences soil functional diversity and microbial community variation, and is closely related to soil quality and health. So it is possible to diagnose soil nutrient status by identifying and quantifying soil microorganisms (Zhang et al., 2002). Phospholipids fatty acid (PLFA) is used widely to indicate soil microbial diversity.

\footnotetext{
Received 2010-02-03, accepted 2010-04-07 doi: 10.3724/SP.J.1227.2010.00107

"Corresponding author: ZhengZhong JIN (E-mail: jinzz@sina.com)
} 
Being a vital component of living biological cell membranes, phospholipids are one of the components of fatty acids with structural diversity and biologic specificity. Thus, the existence and richness of one microbial PLFA can indicate the presence of particular microbial populations. The degree of degradation of phospholipids, which occurs shortly after cell death, can be used to indicate living microbial population (Zelles, 1999). As a result, identifying and quantifying PLFA help us to understand the living cell biomass of soil microbes and microbial population changes (Xue et al., 2008).

However, previous research on soil microorganisms in the Tarim Desert Highway forest land under extreme environmental conditions and drip-irrigation with saline water were limited to simply cultivating the soil microbe and counting the amount of bacteria, actinomycetes and fungi. Culturable soil microorganisms only accounted for $1 \%-3 \%$ of the total. So traditional methods could not comprehensively reveal the soil microbial populations, and, until this study, modern soil microbial ecology methods had not been used to study soil microorganisms in the Tarim Desert Highway forest land. In this study, a combination of cultivation counting methods, and analysis of phospholipids fatty acid methyl esters (being a biomarker method for soil microorganisms), was used to reveal the variations in structure and biomass of soil microbial populations in the Tarim Desert Highway shelter forest land, to provide theoretical support for the sustainable management and extension of the Tarim Desert Highway shelter forest.

\section{Materials and methods}

\subsection{Natural environment characteristics}

Sampling sites were located around the Tazhong oil field in the southeast of the Taklimakan Desert in China (Table 1). Natural environmental conditions along the desert highway can be characterized as an extreme arid climate, scarce surface water resources, highly saline groundwater, strong winds, shifting sand and infertile soils. According to the monitoring data, along the desert highway, the annual precipitation is less than $50 \mathrm{~mm}$; the potential annual evaporation reaches $3,800 \mathrm{~mm}$; the highest temperature is $43.2^{\circ} \mathrm{C}$; the lowest temperature is $-19.3^{\circ} \mathrm{C}$; the maximal wind speed is $24 \mathrm{~m} / \mathrm{s}$, and the time of total annual sand-moving wind with a speed higher than $6.0 \mathrm{~m} / \mathrm{s}$ is from $550 \mathrm{~h}$ to $800 \mathrm{~h}$. The dune morphology in the sampling area is complex and diverse; there are not only longitudinal composite dunes higher than $50 \mathrm{~m}$, but also barchan dunes lower than $1 \mathrm{~m}$ high. The coverage rate of secondary dunes is over $60 \%$, and the annual distance that small dunes move among big composite dunes is more than $15 \mathrm{~m}$. The soil along the desert highway is mainly made up of aeolian sand with weak stability. Natural plants are rare, and the vegetation coverage is very low (Zhou et al., 2002; Li et al., 2004).

\subsection{Plantation pattern of the shelter-forest}

The three shrub species of Calligonium sp., Tamarix sp. and Haloxylon sp., all with high drought- and salinity-tolerance, were selected as the planting species for the shelter forest along the Tarim Desert Highway. The plantation pattern is characterized by mixed inter rows with a $1 \mathrm{~m} \times 1 \mathrm{~m}$ planting space in the $72-78 \mathrm{~m}$ wide shelter forest. The forestland is watered by drip irrigation with underground saline water (salinity = $4.04 \mathrm{~g} / \mathrm{L} ; \mathrm{pH}=8.13$ ). The drip irrigation emitters are spaced $1.5 \mathrm{~m}$ apart, and the irrigation frequency is 10 days with $450 \mathrm{~m}^{3} / \mathrm{hm}^{2}$ irrigation quota. Fertilizer application is mainly in the form of soluble fertilizers

Table 1 Locations of different shelter forest lands

\begin{tabular}{|c|c|c|c|}
\hline No. of sampling sites & Year of forestland establishment & Sites & Geographic coordinate \\
\hline 1 & Control site (drifting sand) & Around T-shape Road Junction in Tazhong & $39^{\circ} 08^{\prime} \mathrm{N}, 83^{\circ} 42^{\prime} \mathrm{E}$ \\
\hline 2 & 2006 & Around planting base of secondary phase Cistanche salsa & $39^{\circ} 08^{\prime} \mathrm{N}, 83^{\circ} 44^{\prime} \mathrm{E}$ \\
\hline 3 & 2005 & Irrigated with No. 69 water well & $38^{\circ} 53^{\prime} \mathrm{N}, 83^{\circ} 13^{\prime} \mathrm{E}$ \\
\hline 4 & 2004 & Around planting base of first phase Cistanche salsa & $39^{\circ} 08^{\prime} \mathrm{N}, 83^{\circ} 43^{\prime} \mathrm{E}$ \\
\hline 5 & 2003 & Around Tazhong Botanical Garden & $39^{\circ} 07^{\prime} \mathrm{N}, 83^{\circ} 42^{\prime} \mathrm{E}$ \\
\hline 6 & 2001 & At southern T-shaped Road Junction & $39^{\circ} 07^{\prime} \mathrm{N}, 83^{\circ} 41^{\prime} \mathrm{E}$ \\
\hline 7 & 1999 & $2 \mathrm{~km}$ away from T-shaped Road Junction & $39^{\circ} 08^{\prime} \mathrm{N}, 83^{\circ} 40^{\prime} \mathrm{E}$ \\
\hline 8 & 1995 & At Zhongsandian in Tazhong & $39^{\circ} 08^{\prime} \mathrm{N}, 83^{\circ} 39^{\prime} \mathrm{E}$ \\
\hline
\end{tabular}


(e.g. urea) applied to the soil in the irrigation water, Once a month through June, July and August, the equivalent of $10-15 \mathrm{~g}$ of fertilizer per plant is applied.

\subsection{Sampling}

Sampling locations were chosen based on similar conditions (site condition, age of plants, surrounding plant species, distance from irrigation emitter, space between plants), and seven forestland sites with different establishment dates and one control site in drifting sand land were selected in July 2006 (Table 1). Five sampling sites with little human disturbance and herbaceous vegetation were chosen in the middle of the shelter forest at each sampling location. Soil samples at $0-10 \mathrm{~cm}, 10-20 \mathrm{~cm}$, and $20-35 \mathrm{~cm}$ were collected with a steel soil auger and the plant residues were discarded. Soil samples from the same layer at each sampling location were fully mixed, immediately put into new sample bags, recorded and then stored in a refrigerator at $4^{\circ} \mathrm{C}$ for microbial population analysis and counting.

\subsection{Experimental analysis}

The number of soil microorganism were determined by the dilution-plate method (Foster et al., 1975; Bagley et al., 1978), and the bacteria, actinomycetes and fungi were cultivated on Beef extract-peptone medium, Gause 1 medium and Potato dextrose agar medium respectively, replicated three times.

Soil microbial populations were analyzed by the FAMEs method (Nancy et al., 2000; Robert et al., 2006). This involves adding a mixture of $15 \mathrm{ml}$ methanol solution and $0.2 \mathrm{~mol} / \mathrm{L} \mathrm{KOH}$ with $3 \mathrm{~g}$ fresh soil to a $50 \mathrm{ml}$ centrifuge tube, which is incubated for $1 \mathrm{~h}$ at $37^{\circ} \mathrm{C}$ while shaking the sample once every 10 min to cause release of fatty acids and ester. Then $3 \mathrm{ml}$ of $1.0 \mathrm{~mol} / \mathrm{L}$ acetic acid solution is added to neutralize the $\mathrm{pH}$; followed by adding and mixing $10 \mathrm{ml}$ $\mathrm{n}$-Hexane to make FAMEs into $\mathrm{n}$-Hexane phase. This is centrifuged at $480 \mathrm{~g}$ for $10 \mathrm{~min}$. After centrifuging, the n-Hexane phase is transferred into a clean test-tube, and the solvent is evaporated under nitrogen gas flow. Finally, the extracted FAMEs (fatty acid methyl esters) are added to $0.5 \mathrm{ml}$ methyl-tertbutyl $(1: 1 \mathrm{v} / \mathrm{v})$ ether solution for GC (gas chromatography) analysis. GC analysis was performed with DB-1 $(30 \mathrm{~m} \times 0.25 \mathrm{~mm}$ $\times 0.25 \mu \mathrm{m})$ chromatographic column (Hewlett-
Packard Co., Palo Alto, Calif.), the range of column temperature was $100-270^{\circ} \mathrm{C}$, raising $5^{\circ} \mathrm{C}$ for a minute. The column was cleaned at $270^{\circ} \mathrm{C}$ for $2 \mathrm{~min}$ between samples.

The microbial fatty acids were identified with a standard substance including 37 kinds of fatty acids (FAs) (SIGMA Company). The FAs' content was determined by quantifying the FAs' peak area using C16: 0 as an internal standard. Different kind of microorganisms have special marker FAs. FAs of $\mathrm{C} 18: 1 \omega 9, \mathrm{C} 18: 2 \omega 6, \mathrm{C} 18: 3 \omega 6$ are viewed as the markers of fungi; bacteria and actinomycetes are in-

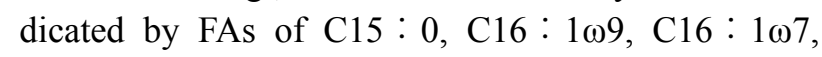
C17 : 0, C18 : $1 \omega 7$ and C10Me18: 0 (Zhang, 2006).

\subsection{Data analysis}

Original data were statistically analyzed by Microsoft Excel 2000 and Statistica 6.0 (Hong, 2002); multiple comparisons were undertaken by Least Significance Difference (LSD). Origin 7.5 and SPSS 12.0 were used to draw the figures (Fang et al., 2006). In all the tables and figures, 1, 2, 3, 4, 6, 8, 12 express soils from the forestlands planted in 2006, 2005, 2004, 2003, 2001, 1999 and 1995 respectively, and 0 a represents control site, drifting sand land.

The content of single FAs were calculated from the ratio of their peak areas to that of the internal standard substance C16: 0 (Kalo et al., 2003; Jesui et al., 2005). Eleven kinds of FAs were identified in all the tested soil samples, including $\mathrm{C} 13: 0, \mathrm{C} 14: 0$, $\mathrm{C} 15: 0, \mathrm{C} 16: 0, \mathrm{C} 16: 1, \mathrm{C} 17: 0, \mathrm{C} 18: 1 \omega 9$, $\mathrm{C} 18: 0, \mathrm{C} 18: 2 \omega 6, \mathrm{C} 18: 3 \omega 3, \mathrm{C} 21: 0$. Principal component analysis (PCA) and regression analysis were performed to the values for their contents. The indexes of soil microbial FAs' diversity, richness and evenness were calculated by the following equations (Zak et al., 1994; Schutter et al., 2001):

$$
\begin{gathered}
H=-\sum_{i=1}^{S} P_{i} \ln p_{i}, \\
E_{\mathrm{H}}=H / H \max =H / \ln S .
\end{gathered}
$$

$H$ expresses soil FAs' diversity index; $P_{i}$ represents percentage content of special FA in total FAs; $E_{\mathrm{H}}$ shows the distribution evenness of FAs; and $S$ (equivalent to the richness of FAs) notes total number of FAs present. 


\section{Results}

\subsection{Changes of soil microbial amount}

Improvement in soil microbial amount implies soil fertility enhancement (Robin et al., 1995). The construction of the Tarim Desert Highway shelter-forest has caused a remarkable increase in the amount of soil microbial activity. The amounts of bacteria, actinomycetes and fungi had significant differences among the different forest land soils $\left(F>F_{0.001}\right)$, with a peak in the 12 year old forest land (established in 1995), which had over 3 times more microbial activity than that found in the drifting sand land (Fig. 1).

The amounts of bacteria, actinomycetes and fungi at the different soil layers showed obvious variation (Fig. 2). The differences between bacteria and actinomycete amounts at different soil depths were significant at 0.01 levels, while those of fungi were significant at 0.05 level. Furthermore, the amounts of bacteria and actinomycetes were significantly different between the soil layers at $20-35 \mathrm{~cm}$ and those at $0-10$ $\mathrm{cm}$ and $10-20 \mathrm{~cm}$, which showed that the bacterial amount of the soil surface layer was more than those of the lower soil layers. Nevertheless, the actinomycetes and fungi amounts of the soil surface layer were smaller than those of the lower soil layers, which may relate to the demands of different microbial developments to soil environmental conditions.

\subsection{Soil microbial fatty acid diversity}

We can see from Table 2 that the soil microbial FAs' Shannon diversity $(H)$, richness $(S)$ and evenness $\left(E_{\mathrm{H}}\right)$ among the different forest lands are obviously different, especially for the indexes of Shannon diversity and evenness, which reached extremely significant levels. The results of multiple comparisons showed that the soil microbial FAs' diversity was enhanced as the age of the forest plantation increased. Compared with the drifting sand land, the soil FAs' diversity increases steadily in the forest land after the year of planting. The trend in the soil microbial FA richness was similar to the diversity, but the evenness did not increase, but decreased slightly with increasing forest age. These results illustrate that planting vegetation on drifting sand land can promote soil microbial development and survival, but the population distribution of the different microorganisms is uneven. The increase in the diversity of soil microbial FA's is mainly contributed by increasing richness in the soil microbial FA's.

We found significant differences in diversity values between the soil layers of $0-10 \mathrm{~cm}, 10-20 \mathrm{~cm}$ and $20-35 \mathrm{~cm}$ through analyzing the results of the soil microbial FA's diversity (Table 3 ). The diversity values for the $10-20 \mathrm{~cm}$ and $20-35 \mathrm{~cm}$ were greater than that of the $0-10 \mathrm{~cm}$. However, the soil microbial FA's richness and evenness do not vary significantly among the different soil layers.

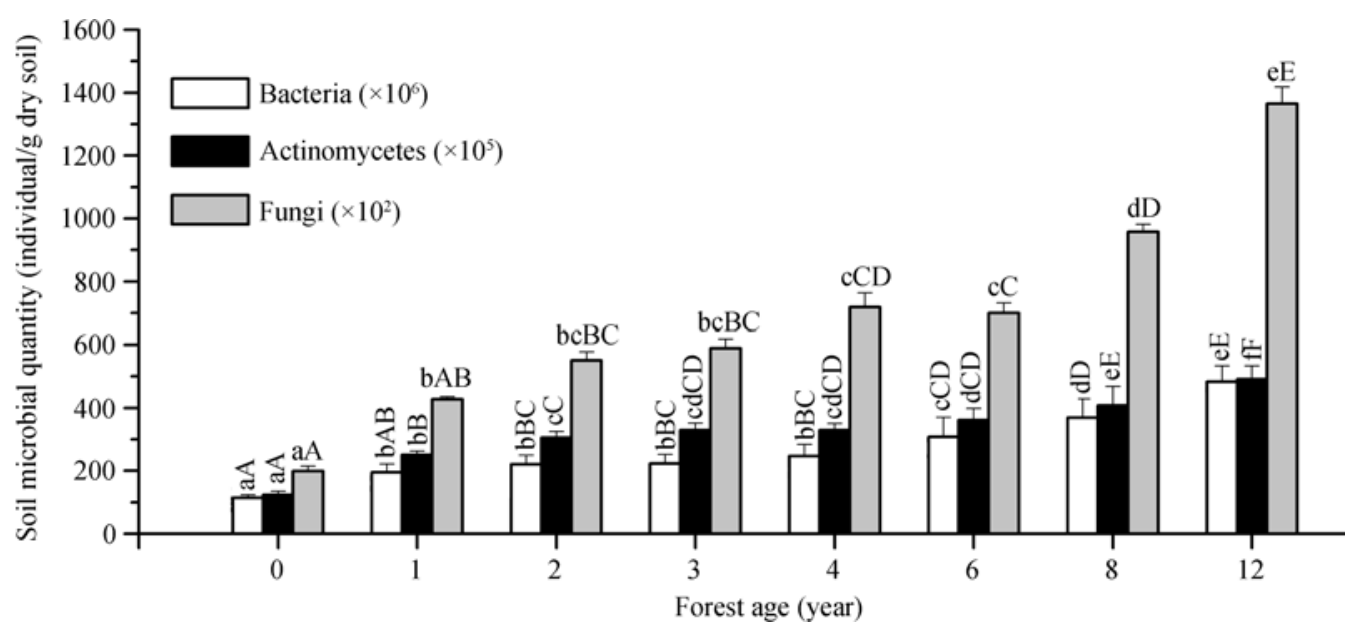

Fig. 1 Soil microbial amounts of the different forest lands. The different capital and lower letters between two forest soils for the same kind of microbe show respectively obvious differences at 0.05 and 0.01 significance levels; the notable $F$ test values for bacteria, actinomycetes and fungi, are respectively $21.08,81.98$ and 37.31 . Vertical bars are S.E. of the mean. 


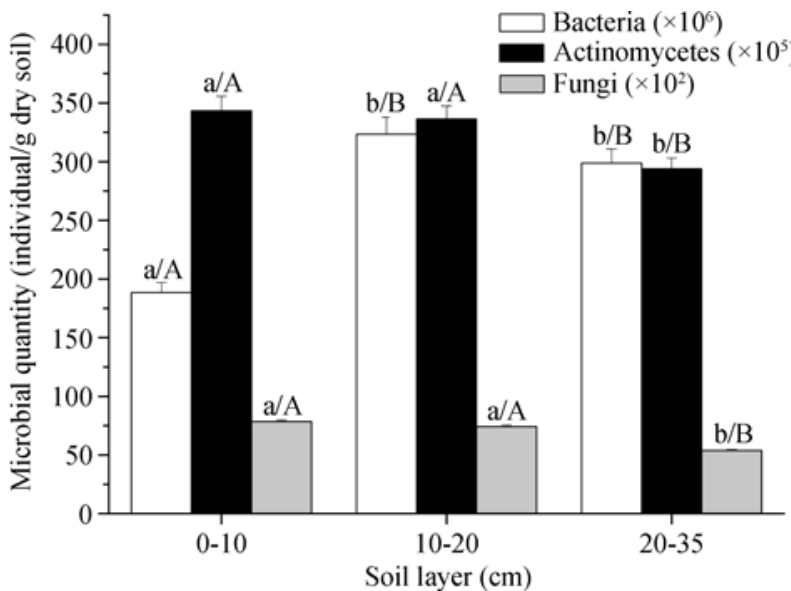

Fig. 2 Soil microbial amounts at the different soil layers. The different capital and lower letters between soil layers for the same kind of microbe show respectively obvious differences at 0.05 and 0.01 significance levels. Vertical bars are S.E. of the mean.

\subsection{Principal component analysis (PCA) of soil microbial FAs}

We selected 11 kinds of the more common FAs that were present in all tested soil samples as the data for PCA (Table 4, Fig. 3). The eigenvalues of the first three Principle Components (PCs) were 5.90, 1.69 and 1.43 , respectively. The cumulative contribution of their variances accounted for $88.37 \%(>80 \%)$ of the information of the primary variables. This was sufficient to allow us to concentrate our analysis on the first three PCs. Among these PCs, the first one included $\mathrm{C} 16: 0, \mathrm{C} 18: 0$ and $\mathrm{C} 14: 0$ (with the greatest contribution ratios) and accounted for $53.66 \%$ of the information of the total variables. Factor loadings at varimax rotation were $0.94,0.92$ and 0.86 , respec-

Table 2 Diversity, richness, evenness indexes for the soil FAs in the different forest lands

\begin{tabular}{|c|c|c|c|}
\hline Forest age (a) & Shannon diversity $(H)$ & Richness $(S)$ & Evenness $\left(E_{\mathrm{H}}\right)$ \\
\hline 0 & $1.92 \pm 0.05 \mathrm{e}$ & $13.33 \pm 0.58 \mathrm{~d}$ & $0.81 \pm 0.06 \mathrm{abc}$ \\
\hline 1 & $2.27 \pm 0.23 \mathrm{de}$ & $19.33 \pm 1.08 \mathrm{~cd}$ & $0.84 \pm 0.03 \mathrm{ab}$ \\
\hline 2 & $2.34 \pm 0.24 \mathrm{cde}$ & $27.67 \pm 1.43 \mathrm{bcd}$ & $0.85 \pm 0.06 \mathrm{a}$ \\
\hline 3 & $2.38 \pm 0.21 \mathrm{cde}$ & $27.67 \pm 1.22 \mathrm{bcd}$ & $0.78 \pm 0.05 \mathrm{abc}$ \\
\hline 4 & $2.58 \pm 0.44 \mathrm{bcd}$ & $29.00 \pm 1.86 \mathrm{abcd}$ & $0.77 \pm 0.03 b c$ \\
\hline 6 & $3.07 \pm 0.37 \mathrm{abc}$ & $36.33 \pm 3.04 \mathrm{abc}$ & $0.77 \pm 0.03 b c$ \\
\hline 8 & $3.12 \pm 0.23 \mathrm{ab}$ & $45.67 \pm 3.33 \mathrm{ab}$ & $0.74 \pm 0.03 \mathrm{c}$ \\
\hline 12 & $3.84 \pm 0.42 \mathrm{a}$ & $47.00 \pm 5.39 \mathrm{a}$ & $0.67 \pm 0.02 \mathrm{~d}$ \\
\hline
\end{tabular}

These are mean values \pm S.E. Values with the same letters are not significantly different at 0.05 levels

Table 3 Diversity, richness, evenness indexes for the soil FAs at the different soil layers

\begin{tabular}{cccc}
\hline Soil layer $(\mathrm{cm})$ & Shannon diversity $(H)$ & Richness $(S)$ & Evenness $\left(E_{\mathrm{H}}\right)$ \\
\hline $0-10$ & $2.54 \pm 0.64 \mathrm{a}$ & $31.38 \pm 2.44 \mathrm{a}$ & $0.77 \pm 0.09 \mathrm{a}$ \\
$10-20$ & $2.79 \pm 0.44 \mathrm{~b}$ & $30.75 \pm 2.10 \mathrm{a}$ & $0.79 \pm 0.06 \mathrm{a}$ \\
$20-35$ & $2.76 \pm 0.37 \mathrm{~b}$ & $30.13 \pm 1.34 \mathrm{a}$ & $0.78 \pm 0.05 \mathrm{a}$
\end{tabular}

Analysis of variance, $F$-values

$3.81^{*}$

$1.97^{\mathrm{NS}}$

$1.84^{\mathrm{NS}}$

These are mean values \pm S.E. Values with the same letters are not significantly different at 0.05 levels. Significant difference at ${ }^{*} P<0.05$ is indicated; ${ }^{\text {NS }}$ indicates no significant differences. $F$-values are shown.

Table 4 Extracted principal components and their eigenvalues

\begin{tabular}{|c|c|c|c|c|}
\hline Principal component & Eigenvalue & Total variance $(\%)$ & Cumulative eigenvalue & Cumulative (\%) \\
\hline 1 & 5.90 & 53.66 & 5.90 & 53.66 \\
\hline 2 & 1.69 & 15.39 & 7.60 & 69.05 \\
\hline 3 & 1.43 & 12.97 & 9.02 & 82.03 \\
\hline
\end{tabular}




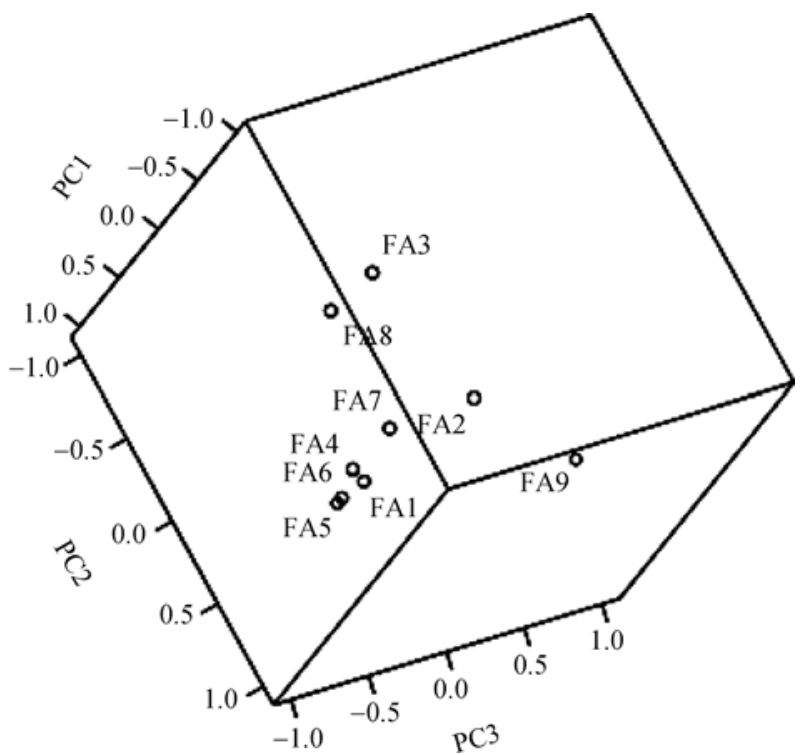

Fig. 3 Principal component loading plots of soil microbial FAs. FA1-9 denotes C16:1, C16:0, C18:1w9, C17:1, C15:1,

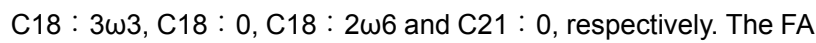
nomenclature follows an express form of $A: B \omega C$ based on standard $\omega$-nomenclature (Zelles, 1999), where ' $A$ ' indicates the total number of carbon atoms, 'B' the number of unsaturated bonds and ' $\omega C$ ' shows the number of $C$ atoms between the aliphatic end of the molecule and the first unsaturated bond.

tively. The second PC included C15:0 and C17 : 0 (which were the FAs that made the biggest contribution) and accounted for $15.39 \%$ of the information of the total variables; their factor loadings were respectively 0.96 and $0.89(>0.80)$. The third PC included C18 : $2 \omega 6$ and C18 : $3 \omega 3$ and accounted for $12.97 \%$ of total variables information (which had maximal contribution ratios), and their factor loadings were 0.93 and $0.88(>0.80)$.

C14:0, C16:0 and C18:0 are widely accepted as the indicators of total soil microbial biomass (Silvie et al., 2003), and found in most soil microbial phospholipids tested in the study. In the first PC, the three kinds of FAs are dominant ones, so the first PC could be viewed as indicative of total soil microbial biomass in the Tarim Desert Highway forest land. C15:0 and $\mathrm{C} 17: 0$ have always been used to estimate bacterial biomass (Sven et al., 2007), and they have the maximal eigenvectors in the second PC, thus the second PC may be regarded as indicative of the soil bacteria. Soil fungi is always marked with $\mathrm{C} 18: 2 \omega 6$ and 18 : $1 \omega 9$ (Frotegard et al., 1993), they make the greatest contribution of FAs to the third PC, and the third PC is viewed as indicative of the soil fungi.

\subsection{Relationships of soil microbial FA's contents and microbial amount}

3.4.1 Regression analysis of the total soil microbial FA

The different soil microbial FAs were identified according to the peak emergence time of the standard substance in the GC analysis. Compared with the internal standard $(\mathrm{C} 16: 0)$, the contents of other FAs were determined by quantifying their peak emergence. We found that the soil microbial FAs' components and contents were obviously different among the different forest lands. In order to screen the FAs for their contributions to the total content of FAs, and to predict the total content of FAs, we defined the different kinds of FAs' contents as independent variables $(x)$, the total FAs' content as dependent variable $(y)$, and chose a Step Regression method to obtain an optimal regression equation shown below:

$$
\begin{aligned}
& y=154.1+3.1 \times 10^{-4} x_{1}+3.5 \times 10^{-4} x_{2}+5.4 \times 10^{-5} x_{3} . \quad \text { (3) } \\
& \left(R^{2}=0.83, p=0.003 ; x_{1}, x_{2}, x_{3} \text { denote } \mathrm{C} 14: 0, \mathrm{C} 16:\right.
\end{aligned}
$$

0 , and $\mathrm{C} 18: 0$, respectively)

Equation 3 indicates positive relationships between the total content of FAs in the soil and the soil contents of $\mathrm{C} 14: 0, \mathrm{C} 16: 0$ and $\mathrm{C} 18: 0$, and a relationship of $\mathrm{C} 16: 0>\mathrm{C} 14: 0>\mathrm{C} 18: 0$, obtained from the step regression coefficients in the equation. Partial correlation analysis of the contents of major FAs (Table 5) showed that a partial correlation coefficient between the $\mathrm{C} 16: 0$ content $\left(x_{2}\right)$ and total FA content $(y)$ reached an extremely high level by T-test, but partial correlation relationships of $\mathrm{C} 14: 0\left(x_{1}\right)$ and $\mathrm{C} 18$ : $0\left(x_{3}\right)$ with total FA content $(y)$ are not obvious. Therefore, it appears that $\mathrm{C} 16: 0$ made the greatest contribution to the total soil FA content; the next is $\mathrm{C} 14: 0$; the least is $\mathrm{C} 18: 0$. Therefore, all the results reflect that components $\mathrm{C} 14: 0, \mathrm{C} 16: 0$ and $\mathrm{C} 18: 0$ are different in microbial phospholipids in the tested soil samples.

3.4.2 Using the analyses of FAs as markers for the soil microbes

Although PLFA exists in all microbial cell membranes, PLFA composition patterns are different in different microbial cell membranes. Previous research indicated that $\mathrm{C} 18: 2 \omega 6, \mathrm{C} 18: 3 \omega 3$ and $\mathrm{C} 18: 1 \omega 9$ are the indicative FAs for fungi (eucaryotic microorganism), 
Table 5 Significance test of FAs with the larger contents

\begin{tabular}{ccccc}
\hline Variable & Partial correlation coefficient & T-test value & Significance level \\
\hline $\mathrm{X}_{1} \rightarrow \mathrm{Y}$ & 0.170 & 0.774 & 0.4482 \\
$\mathrm{X}_{2} \rightarrow \mathrm{Y}$ & 0.771 & 5.418 & 0.0003 \\
$\mathrm{X}_{3} \rightarrow \mathrm{Y}$ & 0.060 & 0.268 & 0.7914 \\
\hline
\end{tabular}

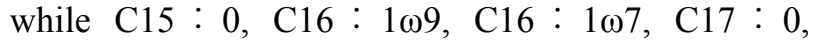
$\mathrm{C} 18: 1 \omega 7$ and $\mathrm{C} 10 \mathrm{Me} 18: 0$ are frequently used as the indicators of bacteria and actinomycetes (prokaryotic microorgan isms) (Zhang, 2006). Among these indicative FAs, only $\mathrm{C} 18: 2 \omega 6, \mathrm{C} 18: 3 \omega 3, \mathrm{C} 15: 0$ and $\mathrm{C} 17: 0$ were identified in all the soil samples that we tested. In order to ensure reliability of the above analysis results, trend-surface analysis (based on least squares theory, as a nonlinear regression analysis method with 2-dimensional high order), was selected

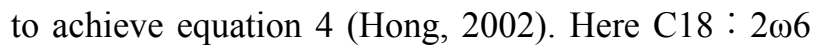
$\left(x_{1}\right)$ and $\mathrm{C} 18: 3 \omega 3\left(x_{2}\right)$ are independent variables, and the quantity of fungi $\left(y_{1}\right)$ is the dependent variable. Similarly, in equation 5, C15:0 $\left(x_{3}\right)$ and C17 : $0\left(x_{4}\right)$ are independent variables and the sum of the amounts of bacteria and actinomycetes $\left(y_{2}\right)$ is the dependent variable. Finally, the observed data of the amounts of soil microbial activity are precisely fitted and explained in the following equations:

Fitted equation for the amount of fungi:

$$
y_{1}=-4.57+2.05 \times 10^{-3} x_{1}+5.90 \times 10^{-4} x_{2}-2.76 \times 10^{-8} x_{1}{ }^{2}+
$$

$3.13 \times 10^{-8} x_{1} \times x_{2}-2.61 \times 10^{-8} x_{2}^{2}$.

$\left(P=0.002\right.$, fitting degree $=99.44 \% ; x_{1}, x_{2}$ respectively denote $\mathrm{C} 18: 3 \omega 3$ and $\mathrm{C} 18: 2 \omega 6)$

Fitted equation for the amount of bacteria and actinomycetes:

$$
\begin{gathered}
y_{2}=-21.32+1.96 \times 10^{-3} x_{3}+1.04 \times 10^{-3} x_{4}-6.72 \times 10^{-8} x_{3}{ }^{2} \\
+1.36 \times 10^{-7} x_{3} \times x_{4}-9.69 \times 10^{-8} x_{4} .
\end{gathered}
$$

$\left(P=0.001\right.$, fitting degree $=99.39 \% ; x_{3}, x_{4}$ denote respectively $\mathrm{C} 15: 0$ and $\mathrm{C} 17: 0)$

From equation 4 , the amount of fungi $\left(y_{1}\right)$ mainly depends on one power term of each of $\mathrm{C} 18: 3 \omega 3$ and C18: $2 \omega 6$, and has close positive relations with them (C18:2 $2 \omega 6>\mathrm{C} 18: 3 \omega 3$ ); but the quadratic terms of the two FAs have weak negative relationships with $y_{1}$. By F-test, this function has a good degree of fit at 99.44\%.

Similarly, equation 5 indicates that the one power term of both $\mathrm{C} 15: 0$ and $\mathrm{C} 17: 0$ makes the greatest contribution to the amount of bacterial and actinomy- cetes $\left(y_{2}\right)$, and the former FA is greater than the latter. Nevertheless, these two FAs' quadratic terms bear a very small negative relationship to the amount of bacteria and actinomycetes $\left(y_{2}\right)$. By F-test, this function also demonstrates a very good degree of fit at $99.39 \%$.

\section{Discussion and conclusion}

In this study, we analyzed soil microbial amounts and their FA contents from the Tarim Desert Highway shelter forest land, and obtained some understanding of the populations of soil microbes and their variations under the effect of the shelter forest.

\subsection{Response of soil microbe to the shelter forest}

Constructing Tarim Desert Highway shelter forest promoted the fixation of the drifting sand land, the formation of the soil physical structure and the accumulation of the soil nutrient, which may have produced better soil environmental conditions for the soil microbial survival and propagation. We found that the soil microbial activity in the forest land soil clearly increased with increasing forest age, enhancing the soil biological activity, which in turn accelerated the development of a blown sand soil. So, we consider that the soil microorganisms in the forest land responded sensitively to the soil formation process of the shelter-forest land. Such soil formation may have been brought about by accumulations of atmospheric dust fall and litter, which triggered increased soil biological activity, including the propagation of bacteria, actinomycetes and fungi. In this way, the planting of vegetation could generate a complex multifunctional biological system (Pang et al., 2004).

\subsection{Population characteristics of the soil microbes in the shelter forest soil}

The results of conventional microbial cultivation showed that the soil microbial populations in the Tarim Desert Highway shelter forest soil and the drifting sand land were dominated by bacteria $(>80 \%$ of the total microbial amount). Analyzing the diversity 
of the soil microbial FAs indicated that construction of the Tarim Desert Highway shelter forest caused enhancement of the diversity in soil microbial FAs, and made the microbe population structure more complex, but had little effect on the evenness of distribution of the soil microbial population. The soil microbial FAs in the Tarim Desert Highway shelter forest land mainly consisted of $\mathrm{C} 14: 0, \mathrm{C} 15: 0, \mathrm{C} 16: 0, \mathrm{C} 17$ :

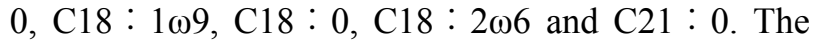
characteristics of this microbial community have been brought about mainly by differences in suitable growing and living environmental conditions for different types of microbial species; bacteria survive in warm and wet environments while fungal growth is easily restrained under poor environmental conditions such as deficient oxygen. The sandy soil conditions of the Tarim Desert Highway shelter forest has high porosity for enhancing drought resistance and heat exchange, which is suitable for bacterial development. So the dominant microbe in the community structure is bacteria (Wall et al., 1999).

\subsection{Signal function of soil microbial PLFA of the shelter forest land}

Analyses of the amount of soil microbial activity and the contents of FAs in soils of the Tarim Desert Highway shelter forest land illustrated that the total soil microbial amount was closely related to the soil contents of $\mathrm{C} 14: 0, \mathrm{C} 16: 0$ and $\mathrm{C} 18: 0$. This agrees with other research and the fact that these PLFAs have frequently been viewed as good biological markers for the amount of soil microbes (Silvie et al., 2003). The soil contents of $\mathrm{C} 15: 0$ and $\mathrm{C} 17: 0$ have been closely correlated with the total amount of soil bacteria, and should be regarded as biological markers for

\section{References}

Bagley S T, Seidler R J. Primary klebsiella identification with Macconkey-inositol carbenicillin agar. Applied Enviromental Microbiology, 1978, 36(4): 536-538.

Fang A P, Ye W P. Origin 7.5 for Technology Plotting and Data Analyzing. Beijing: Machine Industry Press, 2006, 69-76.

Foster R C, Rovira A D. Ultra structure of wheat rhizosphere. New Phytologist, 1975, 76(8): 343-352.

Frotegard A B, Ath E, Tunlid A. Shifts in the structure of soil microbial communities in limed forests as revealed by phospholipids fatty acid analysis. Soil Biology and Biochemistry, 1993, 25(6): 723-732. soil bacteria (Sven et al., 2007). A previously discovered close correlation between $\mathrm{C} 18: 1 \omega 9$ and $\mathrm{C} 18$ : $2 \omega 6$ and the amount of soil fungi (Frotegard et al., 1993) could be used to indicate the level of soil fungi in these shelter forest soils.

Maintaining the stability of the Tarim Desert Highway shelter forest is of great importance. The soil quality of the forest land is crucial to the normal growth of the forest trees, and, being an active factor, soil microorganisms in the forest land ecosystem play an important role in soil nutrient cycling. In addition, changes to soil microbial diversity and population structure can be early-warnings of variations in soil quality. In this study, some characteristics of the soil microbial population in the soil under the Tarim Desert Highway shelter forest were obtained by the FAME method and traditional cultivated method. In the future, we expect molecular biological methods, especially for PCR-DGGE, would be used to study the soil microbial populations of the Tarim Desert Highway forest land. This could contribute in a major way to the comprehensive understanding of the characteristics of soil microbial populations of planted and rehabilitated green land in arid areas.

\section{Acknowledgements}

This project was funded by Western Doctoral Program of Chinese Academy of Sciences, the Innovation Project of Chinese Academy of Science (KZCX2-XB2-13), the National Natural Science Foundation of Xinjiang Uygur Autonomous Region (200821163), and Natural Science Foundation of China (40701098). The authors wish to thank Xinjiang Institute of Ecology and Geography, Chinese Academy of Sciences and Xinjiang Corps' Oasis Agriculture Key Laboratory for providing technical support.

Gu F X, Pan X L, Pan B R, et al. Changing of aeolian soil fertility in central Taklimakan desert under impact of artificial vegetation. Acta Ecologica Sinica, 2002, 22(8): 1179-1188.

Hong N. Statistica for Windows of Statistics and Chart Analyzing Course. Beijing: Beijing Jiaotong University Press, 2002. 179-248.

Jesui V, Nilson E, Regina B. Influence of diets enriched with flaxseed oil on the $\alpha$-linolenic, eicosapentaenoic and docosahexaenoic fatty acid in Nile tilapia. Food Chemistry, 2005, 4(3): 557-560.

Kalo P, Kemppinen A, Ollilainen V, et al. Analysis of regioisomers of short-chain triacylglycerols by normal phase liquid chromatogra- 
phy-electrospray tandem mass spectrometry. International Journal of Mass Spectrometry, 2003, 3(6): 167-180.

Li S Y, Li H Z, Lei J Q, et al. Analysis of growth differences of seedlings irrigated with high degree of mineralization water. Journal of Soil and Water Conservation, 2004, 18(3): 118-122.

Mitchell R J, Campbell C D, Chapman S J, et al. The ecological engineering impact of a single tree species on the soil microbial community. Journal of Ecology, 2010, 98(1): 50-61.

Moore J, Macalady J L, Schulz M S, et al. Shifting microbial community structure across a marine terrace grassland chronosequence, Santa Cruz, California. Soil Biology \& Biochemistry, 2010, 42(1): 21-31.

Moscatelli M C, Fonck M, Angelis P D. Mediterranean natural forest living at elevated carbon dioxide: soil biological properties and plant biomass growth. Soil Use and Management, 2001, 17(5): 195-202.

Nancy J R, Marye S, Richard P D. Use of length heterogeneity PCR and fatty acid methyl ester profiles to characterize microbial communities in soil. Applied Environmental Microbiology, 2000, 66(4): 1668-1675.

Pang X Y, Li Q, Liu S Q, et al. Changes of soil fertility quality properties under subalpine spruce plantation in Western Sichuan. Acta Ecologica Sinica, 2004, 24(2): 261-267.

Robert P, Larkin C, Wayne H. Effect of swine and dairy manure amendments on microbial communities in three soils as influenced by environmental conditions. Biology and Fertility of Soils, 2006, 43(1): 51-61.

Robin O, Roger. Sand, soil, and pigeon droppings: sources of indicator bacteria in the waters of Hanauma Bay, Oahu, Hawaii. Water Science and Technology, 1995, 31(5): 251-254.

Salomo S, Muench C, Roeske, I. Evaluation of the metabolic diversity of microbial communities in four different filter layers of a constructed wetland with vertical flow by biology analysis. Water Research, 2009, 43(18): 4569-4578.

Schutter M E, Dick R P. Shifts in substrate utilization potential and structure of soil microbial communities in response to carbon substrates. Soil Biology and Biochemistry, 2001, 33(3): 1481-1491.

Shan N N, Pan B R, Wen Q K, et al. Study on the ecological characteristics of soil-inhabiting microorganisms of the artificial vegetation in the hinterland of Taklamakan Desert. Arid Zone Research, 2001, 18(4): 52-56

Silvie S, Jarmila L, Martin R. Determination of phospholipids fatty acids in sediments. Chemistry, 2003, 42(5): 39-49.

Sven M, Ellen K, Stefan S. Phospholipid fatty acid profiles and xylanase activity in particle size fractions of forest soil and casts of Lumbricus terrestris L. Applied Soil Ecology, 2007, 5(2): 412-422.

Wall D H, Virginia R A. Control on soil biodiversity: insights from extreme environments. Applied Soil Ecology, 1999, 13: 137-150.

Xue D, Yao H Y, Ge D Y, et al. Soil microbial community structure in diverse land use systems: a comparative study using biolog, DGGE, and PLFA analyses. Pedosphere, 2008, 18(5): 653-663.

Zak J C, Willig M R, Moorhead D L, et al. Functional diversity of microbial communities: a quantitative approach. Soil Biology and Biochemistry, 1994, 26(8): 1101-1108.

Zelles L. Identification of single cultured micro-organisms based on their whole-community fatty acid profiles, using an extended extraction procedure. Chemosphere, 1999, 39(4): 665-682.

Zhang J E. Experimental Technology and Methods Commonly Used in Ecology. Beijing: Chemical Industry Press, 2006. 176-189.

Zhang J E, Liu W G, Hu G. The relationship between quantity index of soil microorganisms and soil fertility of different land use systems. Soil and Environmental Science, 2002, 11(2): 140-143.

Zhou Z B, Li P J, Xu X W, et al. Effect of artificial green belt on salt distribution in sand land in hinterland of Taklimakan Desert. Journal of Soil and Water Conservation, 2002, 16(2): 126-132.

Zhou Z B, Xu X W, Lei J Q, et al. Study on the ecological stability of Tarim Desert Highway shelter forest. Chinese Science Bulletin, 2006, 51(Suppl.1): 126-132. 